also a signal for clear weather. These will be displayed by day and by night by a very simple and suitable contrivance now being perfected by General Myer. In New York already arrangements have been made for displaying the signals to shipping in the harbour from a lofty structure on the roof of the Equitable Life Insurance Company's office, the best station that could be chosen. The display of these storm signals proper will place the American Signal Bureau at once in a position to render inestimable service to shipping and all commercial interests.

These sionals -will at first be neglected by ruder and more unskilful seamen and shippers; but, as in the case of the famous Fitzroy signals on the English coast, every week will add new demonstrations of the value and uility of this system-one of the most splendid gifts bequeathed by modern science to the human race.

The signalling of storms and desolating cyclones to the unsuspecting seaman will, is is believed, mark a new era in our lake and coast navigation, and be the means of annually savirg many lives and millions of dollars' worth of our floating property.

The comparison of these signals with the weather following the signals will be then a matter of special attention. Every discrepancy can then be carefully noted and probed, and every day the meteorologists in charge of the "probabilities" will find the means of rectifying any errors they may have fallen into, and daily increasing the accuracy and perfecting the plan of their forecasts.

The storm signals will be displayed at any hour of the day or night when the instrumental indications give notice of bad weather; and experience has already shown that generally at least tweniy-four hours' forewarning can be given from the central office in Washington of all important weather phenomena. With the telegraph to premonish, forecasts for two or three days in advance are hazardous and unnecessary. For almost all practical purposes of life a day's notice of atmospheric disturbances is quite sufficient, and more reliable than longek premonitions. It will be a grand triumph for American science when the electric telegraph is so utilised that it will bring all citizens of the United States into electric communication with each other, and the most fearful storm, as well as the sunshine and shower, shall be every day a subject of forewarning or congratulation throughout the land, and even on the lakes and oceans that wash the American coasts.

\section{OPENING OF THE MONT CENIS TUNNEL}

$\mathrm{THE}$ project of constructing a tunnel under the Alps 1 -one of the favourite designs of that ardent patriot and eminent statesman, the late Count Cavour- has now been accomplished, thanks to the skill of the Italian engineers. The scientific requirements and methods adopted are well stated in a recent article in the Daily Neres, to which we are indebted for the following interesting particulars:-

The tunnel was commenced on the I 5 th of August, 1857 . The two points at which it was determined to begin the boring were two wretched little Alpine villages, Bardonnecchia and Fourneaux, the former on the Italian, the latter on the French side of Mont Fréjus, the tunnel being nearly pierced under the above-named mountain, and not, as common report would have it, beneath Mont Cenis. These two villages were of the smallest size and most miserable character, and offered no accommodation whatever to the many hundred workmen employed on either side the mountain. Bardonnecchia, on the Piedmontese side, is a village which, in 1857 , when the works commenced, contained about $\mathrm{I}, \mathrm{ooo}$ souls. The houses in it were really little better than huts, being mostly occupied by shepherds, who were aosent with their flocks on the mountains during the summer months. At Fourneaux things were even worse, there being an ordinary population of only 400 inhabitants.

The first problem to be solved, says Mr. Fras. Kossuth, one of the Royal Commissioners of Italian Railways, in his able report on the Mont Cenis Tunnel, was threefold. (i) To fix across the mountain several points which would all be contained in the vertical plane drawn through the axis of the tunnel. (2) To obtain the exact length between the openings. (3) To know the precise difference of level between the two extremities of the tunnel, so as to obtain the proper gradients. In order to execute this programme, a series of observations was established on all the favourable points, and an elaborate trigonometrical survey of the district was commenced. By the end of the season little could be done in the way of surveying; in the winter of the year 1858 all the surveys relating to the alignment and to the length of the tunnel were completed, and all was ready to compile the longitudinal section along the axis of the tunnel. The whole system consisted of twentyeight triangles, and etghty-six was the number of measured angles. All of these were repeated never less than ten times, the greater part twenty, and the most important as many as sixty times. To give the reader an idea of the extraordinary care and accuracy with which the surveying operations were carried out, it may be mentioned that Signor Mondino repeated his experiments for obtaining the level of the tunnel, or rather of the signals over the mountain in 1857 and 1858 , and the difference in the two surveys (over more than 13,000 yards), was only 3.93 inches. Even this was reduced afterwards by Signor Termine to 1.57 inch. The preliminary measurements gave a distance of $13,86 I^{\circ} 5$ yards between the two temporary opeñings. We say temporary openings, because, although the tunnel is itself constructed in a perfectly straight line from Fourneaux to Bardonnecchia, passengers will not pass through the original straight tunnel, but will be conveyed through a branch one which joins the main line a short distance from Fourneaux. The nature of the ground was such as to necessitate the definite and permanent tunnel being taken through the mountain in a curve; but even the unprofessional reader will see that a straight line was indispensable, in order to secure not only accuracy of direction, but also a through draught of air through the whole length of the tunnel. A most important consideration this latter, as one of the main objections brought against the scheme was the supposed difficulty there would be in keeping the tunnel thoroughly well ventilated. It was also much easier to transmit the necessary motive power along a straight line than on a curve. The tunnel, although its axis was straight, was not constructed on a dead level. The gradients were: From the Bardonnecchia (Italian) end, $4,408.50$ feet above the level of the sea, I in 2,000 (O002 per metre) for a distance of 20,99733 feet. From the Fourneaux entrance (French side), 3945 feet above the sea, the rising gradient was I in 434782 ('o23 per metre) for 20,587 feet.

The absolute figures are as follows:

Total length of the tunnel, $13,364.86$ yards.

Elevation above the sea-level of the Bardonneccina Rise of gradient of $\mathrm{I}$ in 2,000 for $20,048^{\circ} \mathrm{feet}^{\circ}$.

Summit level from Bardonnecchia $4,38 I \cdot 25$ 10.024 Elevation above sea-level at Fourneaux entrance
Rise of gradient of $I$ in 45,045 for $200,045^{\circ}$ ro feet.

Summit level from Fourneaux $4,391 \cdot 274$ $3,946 \cdot 50$ 445.00 $4,391 \cdot 50$

This shows a very slight difference from the calculations of the summit level as reckoned at Bardonnecchia, and gives a mean level for the highest point of $4 ; 39$ I 386 feet. The greatest height of the mass of the Alps over the tunnel is 5,307 feet. 
After giving these figures, it may be of interest to present the reader with the account given by an eye-witness, M. Génési, of the meeting of the workmen last winter in the depths of the earth, more than 5,000 feet beneath the summit of Mont Frejus. "On the 9 th of November, 187I," says M. Génési, "I was on my regular round of inspection as usual, when I fancied I heard through the rocks the noise of the explosion of the mines on the Bardonnechia side. I sent a dispatch to discover if the hours agreed. They did, and then there could be no longer any doubt we were nearing the goal. Each following day the explosions were to be heard more and more distinctly. At the beginning of December we heard quite clearly the blows of the perforators against the rocks. Then we vaguely heard the sound of voices. But were we going to meet at the same level and in the same axis? For three days and three nights engineers, foremen, and heads of gangs never left the tunnel. The engineers Borelly and Boni directed the works on the Bardonnechia side, M. Copello on that of Fourneaux. We could not eat or sleep; every one was in a state of fever. At length, on the morning of the 26 th December, the rock fell in near the roof. The breach was made, and we could see each other and shake hands. The same evening the hole was clear-the last obstacle - and the mountain was pierced, our work was done. What a rejoicing we had! In spite of the war, the cheers of all scientitic Europe came to find us in the entrails of our mounta.n when the happy termination of our enterprise became known. The two axes met almost exactly; there was barely half a yard error. The level on our side was only 60 centimetres (less than three-quarters of a yard) too high. But after thirteen years of continual work, who could even hope for so perfect a result? We placed at the point of junction an inscription on a marble tablet, cominemorative of the happy event."

How was the happy event brought about? For the variation of less than a yard in more than 13,000 is surely one of the triumphs of modern engineering slill. We cannot do better than borrow the description of the method pursued given by Mr. Kossuth :- "The observatories placed at the two entrances to the tunnel were used for the necessary observations, and each observatory contained an instrument constructed for the purpose. This instrument was placed on a pedestal of masonry, the top of which was covered with a horizontal slab of marble, having engraved upon its surface two intersecting lines marking a point, which was exactly in the vertical plane containing the axis of the tunnel. The instrument was formed of two supports fixed on a tripod, having a delicate screw adjustment. The telescope was similar to that of a theodolite, provided with cross webs and strongly illuminated by the light from a lantern, concentrated by a lens, and projected upon the cross webs. In using this instrument in checking the axis of the gallery at the northern entrance, for example, after having proved precisely that the vertical flame, corresponding with the point of intersection of the lines upon the slab, also passed through the centie of the instrument, a visual line $w$ as then conveyed to the station at Lachalle (on the mountain), and on the instrument being lowered the required number of points could be fixed in the axis of the tunnel. In executing such an operation it was necessary that the tunnel should be free from smoke or vapour. The point of collimation was a plummet suspended from the roof of the tunnel by means of an iron rectangular frame, in one side of which a number of notches were cut, and the plummet was shifted from notch to notch, in accordance with the signals. of the operator at the observatory. These signals were given to the man whose business it was to adjust the plummet by means of a telegraph or a horn. The former was found invaluable throughout ail these operations. At the Bardonnecchia entrance the instrument employed in setting out the axis of the tunnel was similar to the one already described, with the exception that it was mounted on a little carriage, resting on vertical columns that were erected at distances 500 metres apart in the axis of the tunnel. By the help of the carriage the theodolite was first placed on the centre line approximately. It was then brought exactly into line by a fine adjustment screw, which moved the eye-piece without shifting the carriage. In order to understand more clearly the method of operating the instrument, the mode of proceeding may be described. In setting out a prolongation of the centre line of the tunnel, the instrument was placed upon the last column but one; a light was stationed upon the last column, and exaclly in its centre, and 500 metres ahead a trestle frame was placed across the tunnel. Upon the horizontal bar of this trestle several notches were cut, against which a light was placed and fixed with proper adjusting screws. The observer standing at the instrument caused the light to move upon the trestle frame until it was brought into an exact line with the instrument and the first light, and then the centre of the light was projected with a plummet. In this way the exact centre was found. By a repetition of similar operations the vertical plane containing the axis of the tunnel was laid out by a series of plummet lines. During the intervals that elapsed between consecutive operations with the instruments, the plummets were found to be sufficient for maintaining the direction in making the excavation. To maintain the proper gradients in the tunnel it was necessary at intervals to es:ablish fixed levels, deducing them by direct levelling from standard bench marks placed at short distances from the entrances. The fixed level marks in the inside of the tunnel are made upon stone pillars placed at intervals of 25 metres, and to these were referred the various points in setting out the gradients."

There will be two lines of rail in the tunnel. The vault it self will be six metres high and eight metres wide. The tunnel will be walled in along its whole length, and the lime rock will be nowhere exposed. The thickness of the internal masonry forming the tube is from half a yard to a yard and more, according to circumstances. On the French side the masonry cost on the average 1,300 francs the square metre. On the Italian side only I,000 francs. The tunnel is wonderfully dry in comparison with many smaller works. There is only one subterranean spring of any importance in it. A water-course, or rather aqueduct, has been constructed beneath the permanent way, in order to carry off any water which might drain into the tunnel.

Much has been said about the heat in the tunnel. All accounts agree that it is not excessive, and a recent French visitor to the tunnel gives the following figures:At the entrance, $54^{\circ} \mathrm{Fahrenheit}$; at the telegraph station inside, $76^{\circ}$ Fahrenheit; the average temperature being about $65^{\circ}$ Fahrenheit.

\section{NOTES}

The first session of the Newcastle-on-Tyne College of Physical Science will be opened by inaugural addresses from Professors Herschel, Aldis, Page, and Marreco, from the gth to the I2th of October. The examination for the four exhibitions will be held on the 13th and 14th. On the 19th the Inaugural Ceremony will take place, when the Dean of Durham will deliver an address; after which the successful candidates for the exhibitions will be named. Further particulars are given in our advertising columns,

WE announced some time ago that the Council of the Working Men's College, in Great Ormond Street, was propising a larger infusion of Science in the programme of the College course ; and we are now very glad to be able to state that during the next term, which will commence on October 2 , courses of lectures 